• 研究报告・

\title{
中国裸子植物的物种多样性格局及其影响因子
}

\author{
吕丽莎 1,2 蔡宏宇 ${ }^{2}$ 杨 永 $^{3}$ 王志恒 $^{2^{*}}$ 曾 辉 $^{1}$ \\ 1 (北京大学城市规划与设计学院, 北京大学深圳研究生院, 广东深圳 518055) \\ 2 (北京大学城市与环境学院生态学系, 北京大学生态研究中心, 北京大学地表过程分析与模拟教育部重点实验室, 北京 100871) \\ 3 (中国科学院植物研究所系统与进化植物学国家重点实验室, 北京 100093)
}

摘要: 物种多样性的大尺度空间格局是宏观生态学和生物地理学研究的核心问题之一。本文利用中国裸子植物分 布数据, 结合气候、地形等环境信息, 分析了中国裸子植物物种多样性的大尺度格局及其影响因素, 比较了不同类 群之间物种多样性格局和主导因子的差异, 并探讨了裸子植物在植物区系中所占比重的地理格局。结果表明, 中 国裸子植物的物种多样性总体上呈现南高北低的趋势, 物种多样性在横断山区最高。在裸子植物的三个主要类群 中, 松柏亚纲的物种多样性格局与整体相似, 买麻藤亚纲的多样性高值区则出现在中国西北部的干旱地区, 苏铁 亚纲的分布区较为狭窄, 主要集中在南方地区。线性回归分析结果表明, 空间异质性和降水因子对中国裸子植物 多样性格局的解释率最高, 末次冰期以来的气温变化、海拔高差和能量因子次之。这表明中国裸子植物物种多样 性的格局受到了多种因素的影响, 其中空间异质性和降水因子影响最大。进一步分析发现, 物种多样性格局的主 导因子在不同类群之间具有显著差异, 这可能反映了这些类群的进化历史以及生理适应的差异。裸子植物与被子 植物的比例具有明显的空间格局: 在东部、南部气候环境优越的地区，裸子植物与被子植物的比例低于 0.06 ; 而在 西部、北部等气候环境比较恶劣的地区, 裸子植物的比例则显著上升。回归分析表明, 能量和水分因子显著影响 了裸子植物与被子植物的比例。随着能量的降低和降水的减少, 裸子植物与被子植物的比例会显著升高, 这可能 是由于被子植物在温暖湿润地区具有较强竞争优势, 但裸子植物对极端环境具有更好的适应。

关键词：松柏亚纲; 买麻藤亚纲; 苏铁亚纲; 现代气候假说; 过去气候变化; 物种多样性

\section{Geographic patterns and environmental determinants of gymnosperm species diversity in China}

\begin{abstract}
Lisha Lü ${ }^{1,2}$, Hongyu Cai ${ }^{2}$, Yong Yang ${ }^{3}$, Zhiheng Wang ${ }^{2 *}$, Hui Zeng ${ }^{1}$
1 School of Urban Planning and Design, Peking University Shenzhen Graduate School, Shenzhen, Guangdong 518055

2 Institute of Ecology and Key Laboratory for Earth Surface Processes of the Ministry of Education, College of Urban and Environmental Sciences, Peking University, Beijing 100871

3 State Key Laboratory of Systematic and Evolutionary Botany, Institute of Botany, Chinese Academy of Sciences, Beijing 100093
\end{abstract}

\begin{abstract}
How large-scale patterns of species diversity emerge is a central yet controversial issue in ecology and biogeography. Despite the long history of studies the mechanisms driving species diversity patterns in space remain poorly known. Using distribution data of all gymnosperm species in China, we assessed the influence of environmental factors on spatial patterns of species diversity in China. Further, we evaluated the proportion of gymnosperms in local floras. We found that species diversity of gymnosperms decreases along a south-north axis. Hengduan Mountains, with the highest species diversity, is a hotspot of gymnosperms. Species diversity patterns differ significantly between the gymnosperm subclasses. In particular, the species diversity pattern of Pinidae is similar to that of all species combined, while the species diversity of Gnetidae is highest in the drylands of northwestern China. In contrast, Cycadidae is restricted to southern China. Environmental heterogeneity and precipitation are the best predictors of species diversity patterns of all gymnosperms combined, followed by temperature anomaly since the Last Glacial Maximum (LGM), elevational
\end{abstract}

收稿日期: 2018-04-02; 接受日期: 2018-05-21

基金项目: 科技部重点研发计划(2017YFA0605101)和国家自然科学基金(31522012, 31470564, 31621091)

* 通讯作者 Author for correspondence. E-mail: zhiheng.wang@pku.edu.cn 
range and energy. That different factors predict species diversity patterns of different gymnosperm subclasses, may reflect the differences in their evolutionary history and physiological adaptions. The ratio of gymnosperm to angiosperm species diversity is lower in the warm and humid eastern and southern parts of China, and increases towards the drylands in western and northern parts. Environmental energy and precipitation were good predictors of the ratio of gymnosperms to angiosperms. Specifically, the ratio decreases with increase of energy and decrease of precipitation suggesting that angiosperms may have stronger competitive ability in warm and humid regions while gymnosperms adapt better to dry and cold environments.

Key words: Pinidae; Gnetidae; Cycadidae; contemporary climate hypothesis; past climate change; species diversity pattern

物种多样性的大尺度空间格局是生态学和生 物地理学研究的核心问题之一, 对生物多样性保护 有重要的指导意义(Maurer \& Rosenzweig, 1996)。目 前, 关于物种多样性空间格局的成因, 已有百余种 理论假说(Palmer, 1994; 王志恒等, 2009)。现代气 候、生境异质性和第四纪气候变化对物种多样性格 局的影响在以往研究中被广泛关注和讨论(Jetz \& Rahbek, 2002; Kreft \& Jetz, 2007; Svenning \& Skov, 2007)。大量研究认为现代气候是影响物种多样性格 局的重要因素, 环境能量(Currie, 1991)、水分-能量 动态(water-energy dynamics) (O’Brien, 1998; Hawkins et al, 2003)或冬季严寒(Latham \& Ricklefs, 1993)等过程对物种多样性的限制作用驱动了物种 多样性的大尺度格局。比如, 对非洲(O’Brien, 1998) 和中国(Wang et al, 2011)乔木物种多样性的研究发 现, 水分-能量动态和冬季严寒分别是限制两地乔 木多样性大尺度格局的主导因子。生境异质性假说 认为, 较高的生境异质性可为物种共存提供更多的 生态位，从而容纳更多的物种(Rosenzweig, 1995)。 另外, 地形复杂性高的地区可以通过地理隔离促进 物种的分化, 也可以在气候变化过程中作为物种避 难所而减少物种灭绝, 这些过程都可能增加一个地 区的生物多样性(McCain, 2009; Stein et al, 2014)。近 期研究显示, 现代物种多样性也可能受到了第四纪 气候的影响。在第四纪晚期的末次盛冰期时(约 2.1-1.8万年前), 欧亚大陆与北美北部被大量冰川 覆盖, 造成了大量物种向南方迁移或局地灭绝; 冰 川退却后, 物种重新向北方扩散并形成了现代的物 种多样性格局, 因此末次冰期以来的气候变化是物 种多样性格局的主导因子(Svenning \& Skov, 2007; Sandel et al, 2011)。虽然这些因子对物种多样性格 局的作用均在以往研究中得到不同程度的支持, 但 关于不同因子的相对重要性仍存在争议。同时, 以
往研究多关注脊椎动物和被子植物多样性格局的 成因, 而关于种子植物的原始类群一一裸子植物的 物种多样性格局及其与环境关系的研究仍较少。

裸子植物起源于泥盆纪晚期, 距今已经有 3 亿 多年的历史(Gerrienne et al, 2004; Taylor et al, 2009)。由于现存裸子植物的性状与其祖先具有较高 的相似性(也即性状进化的保守性), 因此长期以来, 裸子植物被认为是植物中的“活化石” (Nagalingum et al, 2011)。然而，近年来一系列关于裸子植物物种 年龄的研究发现, 现生裸子植物中的许多物种起源 于最近两千万年，而苏铁类和北半球的松柏类中的 许多物种, 可能是近几百万年来快速分化而产生的 (Nagalingum et al, 2011; Leslie et al, 2012; Condamine et al, 2015)。这些研究表明, 裸子植物并非是 一个走向衰亡的类群, 而是仍处于活跃的演化过程 中, 并且随着气候环境的变化在不断产生新的适应 性状和新物种分化(Pittermann et al, 2012; Rueda et al, 2017)。在环境的塑造下, 裸子植物进化出了习性 各异的现代类群。现代的裸子植物广布于世界各地, 适应了不同的环境(Wu \& Raven, 1999; Farjon, 2010; Hill, 2012)。在这一过程中, 裸子植物的分布可能同 时受到了现代环境和第四纪气候的影响。

目前, 虽然已有少量研究估算了全球和中国的 裸子植物多样性格局(李果等, 2009; Fragnière et al, 2015), 但关于裸子植物物种多样性的地理格局及 其与环境因子的关系尚缺乏定量研究。另外, 被子 植物自起源后, 其生长速度快、传粉能力强等生理 生态特性使其占领了几乎全部陆地生态系统。自白 严纪以来, 被子植物的竞争可能抢占了裸子植物的 生态位, 从而导致了裸子植物的衰退(Brodribb et al, 2012; Augusto et al, 2014)。但在现代植物区系中, 裸 子植物与被子植物相对贡献的空间格局及其成因 却尚未受到关注与研究。在当前全球气候变化的情 
景下，这不利于我们有效地保护裸子植物。

最新的分类学研究显示, 全球裸子植物共计 1,118种(杨永等, 2017)。其中，中国有197种，占世界 裸子植物物种总数的 $17.6 \%$, 包含裸子植物 4 个主要 类群(杨永等, 2017), 是世界上裸子植物物种最丰富 的国家(Ying et al, 2003)。研究中国的裸子植物多样 性格局及成因, 对于理解世界裸子植物有着重要指 导意义。同时, 中国拥有红豆杉(Taxus)、麻黄 (Ephedra) 等重要药用裸子植物, 了解不同裸子植物 类群的分布格局和成因, 对于种质资源的保护也有 重要意义。

本研究基于《中国木本植物分布图集》(Fang et al, 2011)中的县级物种分布数据, 利用最新的文献 资料对物种分布数据进行了更新, 并估算了中国全 部裸子植物及其各个类群的物种多样性格局。结合 高分辨率的气候、地形和过去第四纪气候变化数据, 分析了物种多样性与环境因子的关系, 并探讨了裸 子植物与被子植物物种数比例的空间格局及其与 环境的关系。这些分析将为理解裸子植物的空间格 局及其与被子植物的相互作用关系提供依据。

\section{数据来源和研究方法}

\section{1 物种分布数据}

本研究使用的裸子植物分布数据来自于《中国 木本植物分布图集》(Fang et al, 2011), 空间分辨率 为县级。我们将其中的裸子植物物种(包括亚种)名 录与最新的《世界裸子植物的分类和地理分布》 (杨 永等, 2017)进行核对校正。为与以往研究相比(如 Qian et al, 2017), 我们将校正后的种下单位(含亚 种、变种等)合并入正种中。最终共获得裸子植物 8 科35属197种的县级分布数据。本文所列的植物均 为中国天然分布的物种, 不包含栽培物种; 其分布 区也为各物种的自然分布区，不包含引种区。

本研究所用中国地图数据来源于国家地球系 统科学数据共享服务平台(http://www.geodata.cn)。 为了消除面积因素的影响, 本研究将中国划分为 3,794 个 $50 \mathrm{~km} \times 50 \mathrm{~km}$ 的等面积网格。每个物种的分 布区与网格进行叠加后得出该物种的网格分布。在 计算多样性时, 统计每个网格中的植物物种数, 作 为该网格的物种多样性。为消除边界及海岸线地区 的网格不完整性对物种多样性估算和统计分析带 来的影响, 后续分析去除了实际面积小于网格面积
$50 \%$ (约1,250 km²)的网格(Wang et al, 2011)。

由于裸子植物的不同类群经历了不同的进化 历史, 有不同的生态适应性; 因此，在分析全部裸 子植物分布格局的同时，我们分别估算了裸子植物 的 3 个主要亚纲(除去单种的银杏亚纲)和 7 个科(除 去单种的银杏科)的物种多样性格局。3个亚纲分别 为松柏亚纲(共158种)、买麻藤亚纲(共23种)、苏铁 亚纲(共15种)。科级分析包含了松科(共85种)、柏科 (共41种)、罗汉松科(共11种)、红豆杉科(共21种)、 麻黄科(共14种)和买麻藤科(共9种)等6科。由于苏铁 亚纲在中国仅有苏铁科单科，我们在科级分析中未 予重复展现。

此外, 为了探讨裸子植物与被子植物的相互作 用关系，我们计算了每个网格中裸子植物与被子植 物的比例。其中, 被子植物的物种多样性为每个网 格中的被子植物物种数, 数据来自Wang等(2011)。

\section{2 环境数据}

为探讨不同环境因子对裸子植物多样性格局 的相对影响，我们选取了4类共13个环境变量。包括: (1)环境能量因子, 包括年均温(MAT)、最冷季均温 (MTCQ)、温暖指数 $(\mathrm{WI}) 、$ 潜在蒸散量 $(\mathrm{PET})$ 。(2) 水分可获得性因子，包括年降水(MAP)、最冷季降 水 $(\mathrm{PCQ})$ 、湿润指数 $(\mathrm{MI})$ 、实际蒸散量 $(\mathrm{AET})$ 。(3) 第四纪气候变化因子, 包括末次冰期以来年均温和 年降水的变化(MATano、MAPano)。(4)生境异质性 因子, 包括海拔高差(ER)、年均温空间变异(TR)和 年降水空间变异(PR)。在以往研究中, 这些变量都 被证明与物种多样性具有较强的相关性。

本研究所用的气候数据中, 年均温、最冷季均 温、年降水、最湿季降水、末次冰期时的年均温和 年降水数据来自于世界气候数据库 (http://www. worldclim.org/), 数据分辨率约为 $1 \mathrm{~km} \times 1 \mathrm{~km}$ 。末次 冰期以来的气候变化以末次冰期时的年均温和年 降水的距平(anomaly)表征, 计算方式分别为现代年 均温或年降水与末次冰期时的年均温与年降水的 差。在以往研究中, 末次冰期时的年均温和年降水 的距平被广泛用于评估第四纪气候变化对物种分 布和物种多样性的影响(如Araújo et al, 2008; Sandel et al, 2011)。潜在蒸散量、实际蒸散量和湿润指数 根据Thornthwaite和Hare (1955)计算。其中, 潜在蒸 散量常被用来反映一个地区的能量水平(Currie, 1991), 而实际蒸散量和湿润指数则常被用来反映 
一个地区的水分条件(Wang et al, 2011)。温暖指数定 义为月均温大于 $5^{\circ} \mathrm{C}$ 的气温之和, 反映了一个地区 的积温水平(Fang \& Yoda, 1990)。海拔高差通常被 用来反映一个地区的地形复杂程度, 而年均温和年 降水的空间变异则被用来反映一个地区的气候复 杂程度(Stein et al, 2015)。海拔数据来自美国地质调 查局 (USGS) 的数字高程模型 (DEM)(https://ta.cr. usgs.gov/GTOPO30), 空间分辨率为 $1 \mathrm{~km} \times 1 \mathrm{~km}$; 海 拔高差为每个 $50 \mathrm{~km} \times 50 \mathrm{~km}$ 网格内最大值与最小 值的差。这些数据与 $50 \mathrm{~km} \times 50 \mathrm{~km}$ 的网格进行叠 加后得到每个网格的平均气候指标。

\section{3 数据处理}

本研究采取一元线性回归模型分析裸子植物 物种多样性格局与环境因子的关系。为消除数据非 正态性对回归分析的影响, 对因变量(物种多样性、 裸子植物与被子植物的比例)和3个环境异质性因子 (海拔高差、年均温空间变异和年降水空间变异)进 行了对数转化。物种多样性格局、裸子植物与被子 植物比例的空间格局以及环境数据中, 均存在显著 的空间自相关，这会使得在检验回归模型显著性时， 倾向于获得更为显著的结果, 从而产生第一类错误 (Lennon, 2000)。为了消除数据的空间自相关对模型 显著性的影响，使用改进 $t$ 检验方法(Dutilleul et al, 1993)对回归结果进行显著性检验, 取 $P<0.05$ 的结 果作为显著性结果。使用回归模型的相关系数 $r$ 评估 环境因子对物种多样性以及裸子植物与被子植物 比例空间格局的解释率。

为进一步比较不同类型环境变量的组合对于 裸子植物物种多样性空间格局的影响，我们建立了 全部裸子植物及不同类群的物种多样性与环境因 子的最优线性模型。由于同一类环境因子中的不同 变量之间通常具有较强的相关性(附录1)。为降低多 重共线性对模型的影响, 我们从4类环境因子中各 选取一个变量作为自变量进行模型构建。利用穷举 法建立了包含4类环境因子中所有变量的可能组合, 并以模型校正拟合优度(adjust $R^{2}$ )选出最优模型, 然后通过比较各个模型中各变量的偏决定系数 (partial $R^{2}$ )来比较不同环境因子对模型的贡献。我们 为全部裸子植物及不同类群的物种多样性格局分 别建立了最优模型。

本文的统计分析在R 3.3.1 (R Core Team, 2016) 中进行。其中, 一元线性回归使用了 $1 \mathrm{~m}$ 函数, 调整
$R^{2}$ 的计算使用了 anova 函数, 改进 $t$ 检验使用了 SpatialPack 程序包 (Osorio et al, 2016) 中的 modified.ttest函数。

\section{结果}

\section{1 裸子植物的多样性格局}

裸子植物在中国分布较广，几乎遍及全国，其 物种多样性呈南高北低的基本格局(图1a)。中国西 南的横断山区是裸子植物的多样性中心; 在广西北 部、华中和福建的山地地区，裸子植物的物种多样 性也较高。在青藏高原、西北地区、华东地区和东 北平原，裸子植物的物种多样性较低(图1a)。

裸子植物 3 个主要类群的物种多样性格局如下:

(1)松柏亚纲。作为中国裸子植物的主要成分, 松柏亚纲与全部裸子植物的多样性格局和分布热 点区基本一致，但其在西北干旱地区的分布很少或 没有分布(图1c)。在科水平上，松科、柏科的多样性 格局与整体也较为相近, 多样性中心均位于西南的 横断山区(图2a，b)。罗汉松科和红豆杉科的天然分 布区位于中国南方，但其物种多样性格局略有差异： 罗汉松科物种多样性在海南岛最高，而红豆杉科物 种多样性最高的地区则位于广西北部、华中和福建 武夷山地区(图2c, d)。

(2)买麻藤亚纲。买麻藤亚纲与裸子植物整体分 布趋势不同，其物种多样性在西北干旱区较高，准 噶尔盆地以及青藏高原北缘均为买麻藤类的分布 热点区(图1e)。买麻藤亚纲下两个科的多样性格局 有明显的差异：麻黄科主要分布于非季风区，在干 旱地区的多样性较高; 买麻藤科主要分布于华南及 周边各省区，在中国的分布区域较为狭小，仅占约 $11 \%$ 的面积(图2e, f)。买麻藤科物种在中国多为狭域 分布, 仅少数物种分布范围较广, 例如小叶买麻藤 (Gnetum parvifolium)、买麻藤(G. montanum) 和垂子买 麻藤 (G. pendulum)。

(3)苏铁亚纲。苏铁类主要分布于热带地区，喜 温暖湿润的环境, 因此在中国的分布范围较小, 主 要限于南亚热带地区，分布面积仅占国土面积的约 8\%, 其物种多样性格局也与中国裸子植物的整体 格局不同(图1g)。苏铁物种多样性在云南东南部、 广西西北部和海南岛较高, 约有5-7种，其余大部 分地区仅有1-2种分布。另一方面，苏铁类各物种的 分布区均较狭小，即使分布较广的物种，如宽叶苏 

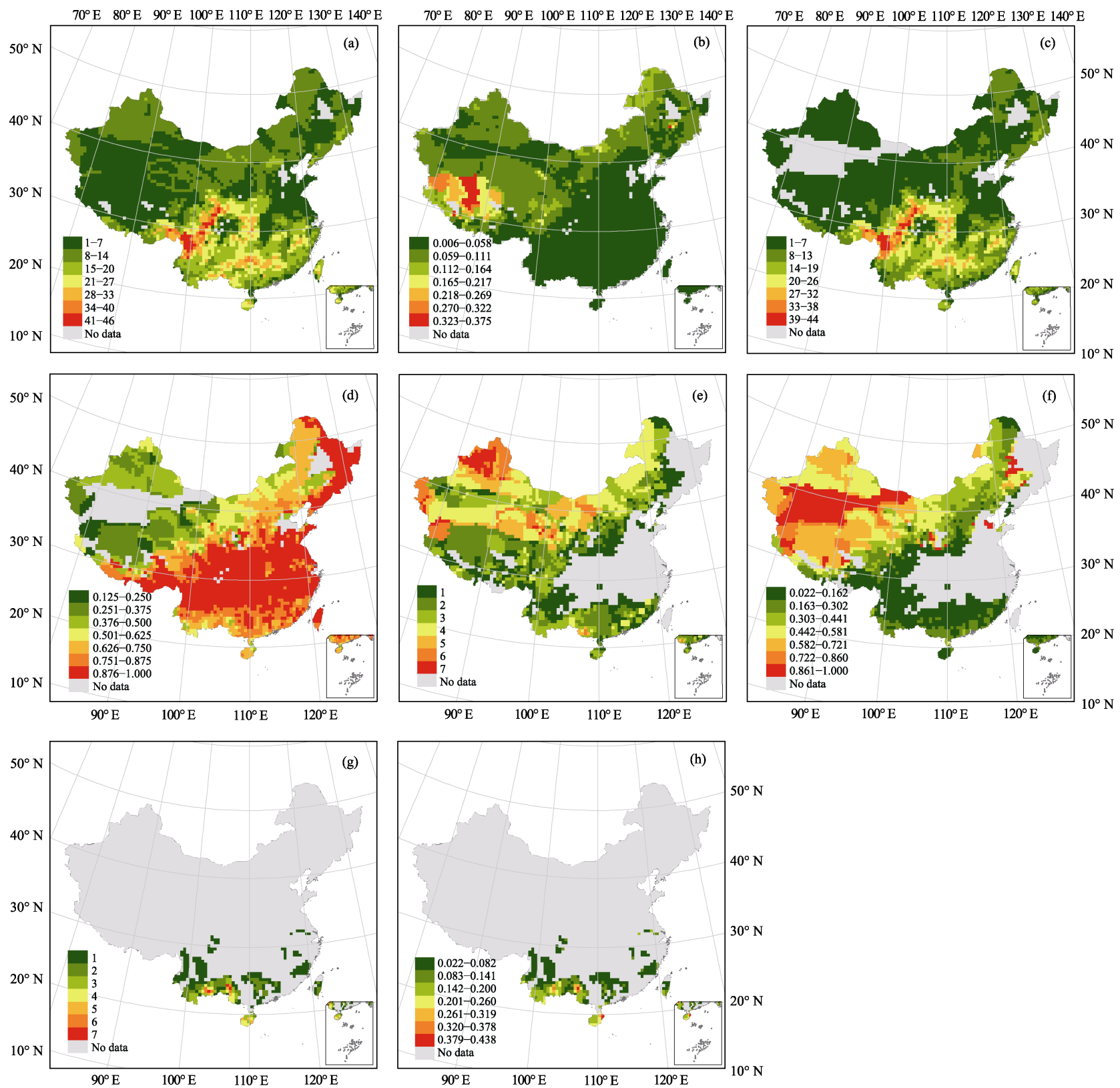

图1 中国裸子植物物种多样性格局。(a)全部裸子植物物种多样性; (b)裸子植物与被子植物的比例; (c)松柏亚纲物种多样性; (d)松柏亚纲与全部裸子植物的比例; (e)买麻藤亚纲物种多样性; (f)买麻藤亚纲与全部裸子植物的比例; (g)苏铁亚纲物种多样 性; (h)苏铁亚纲与全部裸子植物的比例。

Fig. 1 Species diversity patterns of gymnosperms in China. (a) Species diversity of all gymnosperms; (b) Ratio of gymnosperms to angiosperms; (c) Species diversity of Pinidae; (d) Ratio of Pinidae to all gymnosperms; (e) Species diversity of Gnetidae; (f) Ratio of Gnetidae to all gymnosperms; (g) Species diversity of Cycadidae; (h) Ratio of Cycadidae to all gymnosperms.

铁(Cycas balansae)、苏铁 (C. revoluta)、闽粤苏铁 $(C$. taiwaniana) 和四川苏铁(C. szechuanensis), 也仅分 布在有限的范围内; 其余物种分布范围更为狭小。

\section{2 裸子植物物种多样性与环境因子的关系}

中国裸子植物物种多样性与年均温 $(r=0.278)$ 、 最冷季均温 $(r=0.338)$ 、年降水 $(r=0.478)$ 、最冷季 降水 $(r=0.332)$ 、湿润指数 $(r=0.491)$ 、实际蒸散量 $(r=0.391)$ 、海拔高差 $(r=0.484)$ 、年均温空间变异 $(r=0.462)$ 和年降水空间变异 $(r=0.556)$ 呈显著正相 关 $(P<0.05)$, 与末次冰期以来的气温变化 $(r=$ $-0.400)$ 呈显著负相关 $(P<0.05)$ (表1)。生境异质性因 子对全部裸子植物物种多样性格局的影响最大。

裸子植物 3 个主要类群的物种多样性格局与环 境因子的关系如下: 

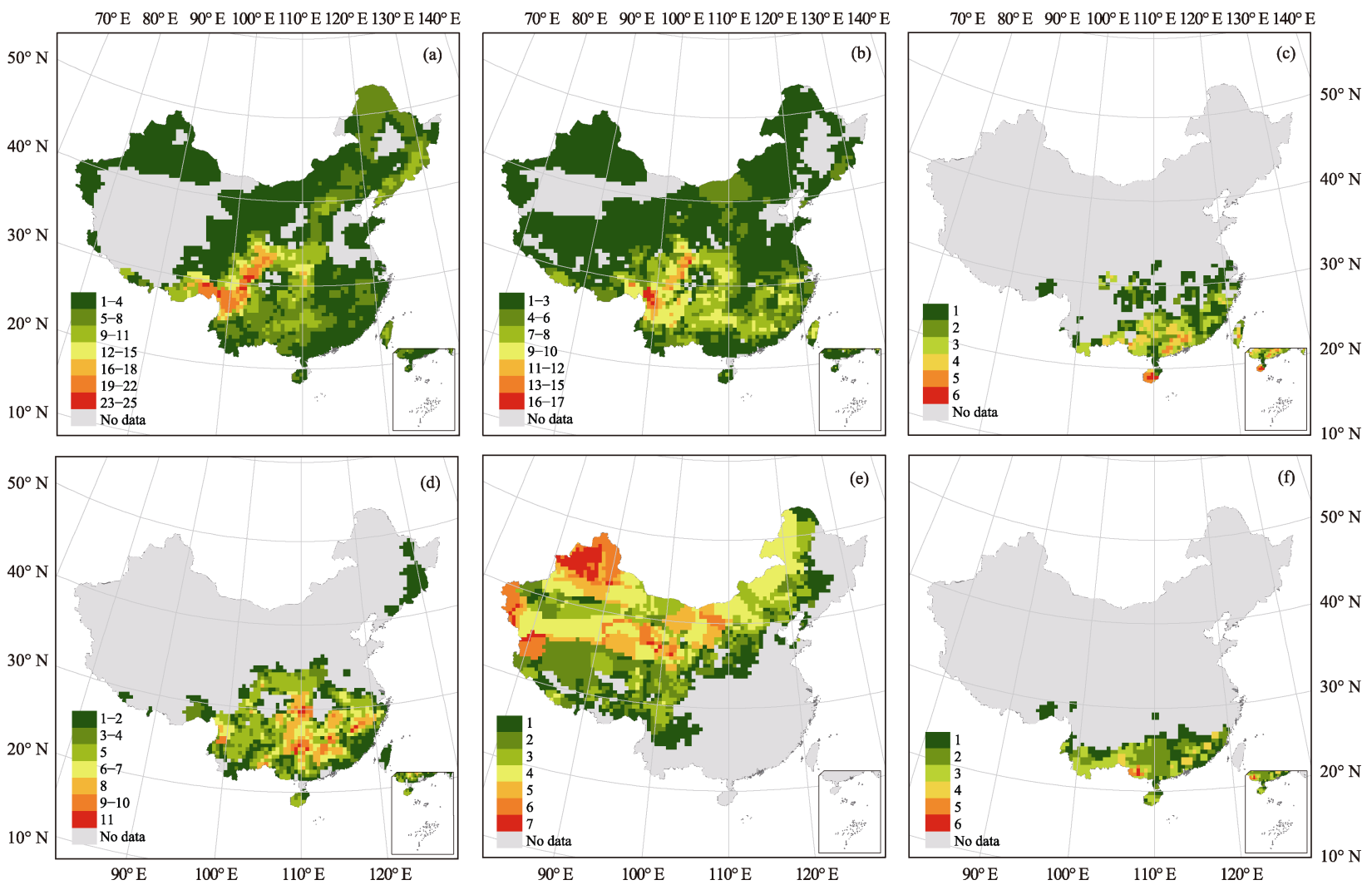

图2 中国裸子植物各科物种多样性格局。(a)松科; (b)柏科; (c)罗汉松科; (d)红豆杉科; (e)麻黄科; (f)买麻藤科。

Fig. 2 Species diversity patterns of gymnosperms in China. (a) Pinaceae; (b) Cupressaceae; (c) Podocarpaceae; (d) Taxaceae; (e) Ephedraceae; (f) Gnetaceae.

表1中国全部裸子植物及不同类群的物种多样性和裸子植物与被子植物比例与环境因子的单因素相关关系 $(R)$

Table 1 Bivariate correlations $(R)$ between species diversity of all gymnosperm species, species diversity of gymnosperms in different clades, ratio of all gymnosperms to angiosperms and environmental determinants in China

\begin{tabular}{|c|c|c|c|c|c|c|c|c|c|c|c|}
\hline $\begin{array}{l}\text { 环境变量 } \\
\text { Environmental } \\
\text { determinants }\end{array}$ & $\begin{array}{l}\text { 全部All } \\
\text { gymno- } \\
\text { sperms }\end{array}$ & $\begin{array}{l}\text { 比例 } \\
\text { Ratio }\end{array}$ & $\begin{array}{l}\text { 松柏亚纲 } \\
\text { Pinidae }\end{array}$ & $\begin{array}{l}\text { 买麻藤亚纲 } \\
\text { Gnetidae }\end{array}$ & $\begin{array}{l}\text { 苏铁亚纲 } \\
\text { Cycadidae }\end{array}$ & $\begin{array}{l}\text { 松科 } \\
\text { Pinaceae }\end{array}$ & $\begin{array}{l}\text { 柏科 } \\
\text { Cupres- } \\
\text { saceae }\end{array}$ & $\begin{array}{l}\text { 罗汉松科 } \\
\text { Podocar- } \\
\text { paceae }\end{array}$ & $\begin{array}{l}\text { 红豆杉科 } \\
\text { Taxaceae }\end{array}$ & $\begin{array}{l}\text { 麻黄科 } \\
\text { Ephed- } \\
\text { raceae }\end{array}$ & $\begin{array}{l}\text { 买麻藤科 } \\
\text { Gnetaceae }\end{array}$ \\
\hline MAT & $0.278 *$ & $-0.826^{*}$ & $0.501^{*}$ & $-0.266^{*}$ & $0.455^{*}$ & 0.115 & $0.376^{*}$ & $0.421 *$ & $0.352 *$ & $-0.198 *$ & $0.342^{*}$ \\
\hline MTCQ & $0.338 *$ & $-0.805^{*}$ & $0.504 *$ & $-0.378^{*}$ & $0.535^{*}$ & $0.207 *$ & $0.417 *$ & $0.476^{*}$ & $0.366^{*}$ & $-0.397 *$ & $0.394 *$ \\
\hline WI & 0.232 & $-0.790 *$ & $0.429 *$ & $-0.191 *$ & $0.467 *$ & 0.024 & $0.277^{*}$ & $0.429 *$ & $0.230 *$ & -0.084 & $0.346^{*}$ \\
\hline PET & 0.212 & $-0.778^{*}$ & $0.426^{*}$ & $-0.182^{*}$ & $0.426^{*}$ & 0.007 & $0.274 *$ & $0.395^{*}$ & $0.233^{*}$ & -0.076 & $0.274 *$ \\
\hline MAP & $0.478 *$ & $-0.706^{*}$ & $0.615^{*}$ & $-0.423^{*}$ & 0.044 & $0.365^{*}$ & $0.449 *$ & $0.286^{*}$ & $0.313^{*}$ & $-0.520 *$ & 0.105 \\
\hline PCQ & $0.331 *$ & $-0.117^{*}$ & $0.416^{*}$ & $-0.288^{*}$ & $-0.169 *$ & 0.113 & $0.323^{*}$ & 0.087 & $0.303^{*}$ & $-0.291^{*}$ & $-0.117^{*}$ \\
\hline MI & $0.491 *$ & $-0.469 *$ & $0.617^{*}$ & $-0.465^{*}$ & $-0.222 *$ & $0.529 *$ & $0.485^{*}$ & 0.028 & $0.230 *$ & $-0.467^{*}$ & $-0.132 *$ \\
\hline AET & $0.391^{*}$ & $-0.748^{*}$ & $0.555^{*}$ & $-0.459 *$ & $0.403^{*}$ & $0.336 *$ & $0.350 *$ & $0.392 *$ & $0.246^{*}$ & $-0.547^{*}$ & $0.291^{*}$ \\
\hline ER & $0.484 *$ & 0.080 & $0.333^{*}$ & 0.006 & $-0.164 *$ & $0.335 *$ & $0.321 *$ & 0.066 & $0.187^{*}$ & 0.012 & -0.088 \\
\hline TR & $0.462 *$ & 0.089 & $0.313^{*}$ & -0.015 & $-0.140^{*}$ & $0.334 *$ & $0.306^{*}$ & 0.071 & $0.163^{*}$ & -0.014 & -0.067 \\
\hline PR & $0.556^{*}$ & $-0.431 *$ & $0.614^{*}$ & $-0.228^{*}$ & 0.092 & $0.412 *$ & $0.486^{*}$ & 0.068 & $0.166^{*}$ & $-0.185^{*}$ & $-0.139 *$ \\
\hline MATano & $-0.400 *$ & $0.517^{*}$ & $-0.407^{*}$ & 0.047 & $-0.546^{*}$ & -0.042 & $-0.399 *$ & $-0.551^{*}$ & $-0.376^{*}$ & $-0.120^{*}$ & $-0.451^{*}$ \\
\hline MAPano & 0.001 & -0.099 & 0.020 & -0.033 & $0.170^{*}$ & $-0.079 *$ & $-0.112^{*}$ & $0.501^{*}$ & $-0.113^{*}$ & $0.132 *$ & $0.192 *$ \\
\hline
\end{tabular}

* $P<0.05$ 。 MAT: 年均温; MTCQ: 最冷季均温; WI: 温暖指数; PET: 潜在蒸散量; MAP: 年降水; PCQ: 最冷季降水; MI: 湿润指数; AET: 实际蒸散量; ER: 海拔高差; TR: 年均温空间变异; PR: 年降水空间变异; MATano: 末次冰期以来年均温变化; MAPano: 末次冰期以来年降水变化。

MAT, Mean annual temperature; MTCQ, Mean temperature of coldest month; WI, Warmth index; PET, Potential evapotranspiration; MAP, Annual precipitation; PCQ, Precipitation of coldest month; MI, Moist index; AET, Actual evapotranspiration; ER, Elevational range; TR, Environmental heterogeneity of temperature; PR, Environmental heterogeneity of precipitation; MATano, Temperature anomaly since the Last Glacial Maximum; MAPano, Precipitation anomaly since the Last Glacial Maximum. 
(1)松柏亚纲。其物种多样性与除末次冰期以来 降水变化之外的全部环境因子显著相关 $(P<0.05)$ 。 除与末次冰期以来的气温变化 $(r=-0.407)$ 呈负相关 外, 与其他变量呈正相关, 其中与湿润指数 $(r=$ $0.617) 、$ 平均年降水 $(r=0.615) 、$ 年降水空间变异 $(r=$ $0.614)$ 、实际蒸散量 $(r=0.555)$ 相关性最强。松科与 年平均降水 $(r=0.365)$ 、湿润指数 $(r=0.529)$ 、实际 蒸散量 $(r=0.336)$ 、海拔高差 $(r=0.333)$ 、年均温空 间变异 $(r=0.334) 、$ 年降水空间变异 $(r=0.412)$ 呈显 著正相关 $(P<0.05)$, 与末次冰期以来降水变化 $(r=$ $-0.079)$ 呈显著负相关 $(P<0.05)$ 。柏科与末次冰期以 来气温和降水变化呈显著负相关, 与其他所有环境 因子均显著正相关 $(P<0.05)$, 其中与年降水空间变 异 $(r=0.486)$ 、湿润指数 $(r=0.485)$ 和年平均降水 $(r=$ $0.449)$ 的关系最强。罗汉松科与湿润指数、最冷季 降水及 3 个气候异质性因子无显著相关, 与其他因 子显著相关 $(P<0.05)$, 其中与末次冰期以来气温变 化显著负相关，与其他因子呈正相关; 其与末次冰 期以来气温变化 $(r=-0.551) 、$ 降水变化 $(r=0.501)$ 和最冷季均温 $(r=0.476)$ 相关性最强。红豆杉科与全 部因子显著相关 $(P<0.05)$, 除与末次冰期以来的气 温变化 $(r=-0.376)$ 和降水变化 $(r=-0.113)$ 呈负相关 外, 与其他变量呈正相关; 其与末次冰期以来气温 变化 $(r=-0.376)$ 、最冷季均温 $(r=0.366)$ 和年均温 $(r$ $=0.352)$ 关系最强。

(2)买麻藤亚纲。其物种多样性与能量和水分因 子及年降水的空间变异均显著负相关 $(P<0.05)$ 。其 中, 物种多样性与湿润指数 $(r=-0.465)$ 、实际蒸散 量 $(r=-0.459)$ 、年降水 $(r=-0.423)$ 的相关性最强。 麻黄科物种多样性与除温暖指数、潜在蒸散量、海 拔高差和年均温空间变异之外的因子均显著相关 $(P<0.05)$, 其中, 与末次冰期以来降水变化 $(r=$ 0.132)呈显著正相关, 与其他因素呈显著负相关, 并且与降水因子负相关最强(实际蒸散量: $r=$ -0.547 , 年平均降水: $r=-0.520$, 湿润指数: $r=$ $-0.467)$ 。买麻藤科物种多样性与除年均温、年均温 空间变异和海拔高差外的全部因子显著相关 $(P<$ $0.05)$, 其中与湿润指数 $(r=-0.132)$ 、最冷季降水 $(r=$ $-0.117) 、$ 年降水空间变异 $(r=-0.139)$ 和末次冰期以 来气温变化 $(r=-0.451)$ 呈负相关, 与其他因子呈正 相关; 其中与末次冰期以来气温变化 $(r=-0.451)$ 、 最冷季均温 $(r=0.394)$ 和温暖指数 $(r=0.346)$ 相关性
最强。

(3)苏铁亚纲。与除年降水和年降水空间变异以 外的全部变量均显著相关。其中年均温 $(r=0.455)$ 、 最冷季均温 $(r=0.535)$ 、温暖指数 $(r=0.467)$ 、潜在 蒸散量 $(r=0.457)$ 、实际蒸散量 $(r=0.403)$ 、末次冰 期以来降水变化 $(r=0.170)$ 呈显著正相关 $(P<0.05)$, 与最冷季降水 $(r=-0.169)$ 、湿润指数 $(r=-0.219)$ 、 海拔高差 $(r=-0.164)$ 、年均温空间变异 $(r=-0.140)$ 和末次冰期以来气温变化 $(r=-0.546)$ 呈显著负相关 $(P<0.05)$ 。其与末次冰期以来气温变化、最冷季均 温和温暖指数相关性最强。

\section{3 中国裸子植物与环境因子的最优线性模型}

对于全部裸子植物，海拔梯度、潜在蒸散量、 湿润指数和末次冰期以来气温变化组成的多元线 性模型可以在一定程度(43.6\%)上解释其多样性格 局; 海拔梯度影响最大, 偏决定系数为 0.171 (表2)。

裸子植物 3 个主要类群物种多样性格局的最优 线性模型如下:

(1)松柏亚纲。年均温、湿润指数、海拔梯度和 末次冰期来气温变化总共解释了 $52.7 \%$ 的多样性格 局。对于松科, 湿润指数是影响最大的变量(偏决定 系数为 0.194$)$, 与海拔梯度、末次冰期以来气温变化 和年均温共同解释了 $33.1 \%$ 的多样性格局。柏科中, 年均温、年均温空间变异、湿润指数和第四纪以来 降水变化共同解释了 $36.1 \%$ 的多样性格局。罗汉松 科中, 第四纪以来气温变化是影响最大的变量(偏 决定系数 0.144$)$, 和年均温空间变异、潜在蒸散量和 湿润指数共同解释 $37.5 \%$ 的多样性格局。红豆杉科 中, 环境因子对其影响稍弱, 海拔梯度、最冷季降 水、年均温和第四纪以来降水变化共同解释了 28.4\%的多样性格局。

(2)买麻藤亚纲。最冷季均温、湿润指数、末次 冰期以来气温变化和年降水空间变异总共解释了 $36.5 \%$ 的多样性格局。实际蒸散量、最冷季均温、 末次冰期以来气温变化和年降水空间格局解释了 $43.2 \%$ 的麻黄科分布格局; 末次冰期以来气温变化、 海拔梯度、最冷季均温和最冷季降水解释了 $32.1 \%$ 的买麻藤科的分布格局。

(3)苏铁亚纲。末次冰期以来气温变化、最冷季 降水、年降水空间变异和最冷季均温共同解释了 $42.4 \%$ 的多样性格局。其中末次冰期以来气温变化 的影响最大, 偏决定系数达到了 0.151 。 
表2 中国裸子植物及主要类群物种多样性与环境因子的最优线性模型 $(\boldsymbol{P}<0.01)$

Table 2 Environmental determinants of species diversity for all gymnosperm species, species diversity of gymnosperms in different clades and ratio of all gymnosperms to angiosperms in China from best-fit explanatory models

\begin{tabular}{|c|c|c|c|c|c|c|}
\hline & & $\begin{array}{l}\text { 校正后模型解释率 } \\
\text { Adjust } R^{2}\end{array}$ & $\begin{array}{l}\text { 能量 } \\
\text { Energy factors }\end{array}$ & $\begin{array}{l}\text { 水分 } \\
\text { Precipitation } \\
\text { factors }\end{array}$ & $\begin{array}{l}\text { 异质性 } \\
\text { Environmental } \\
\text { heterogeneity }\end{array}$ & $\begin{array}{l}\text { 过去气候变化 } \\
\text { Climate anomaly }\end{array}$ \\
\hline \multirow{3}{*}{$\begin{array}{l}\text { 裸子植物 } \\
\text { All } \\
\text { gymnosperms }\end{array}$} & 变量 Variables & \multirow[t]{3}{*}{0.436} & PET & MI & ER & MATano \\
\hline & 偏决定系数 Partial $R^{2}$ & & 0.037 & 0.081 & 0.171 & 0.010 \\
\hline & $\begin{array}{l}\text { 标准化系数 } \\
\text { Standardized coefficient }\end{array}$ & & 0.228 & 0.255 & 0.464 & -0.107 \\
\hline \multirow{3}{*}{$\begin{array}{l}\text { 裸子植物/ } \\
\text { 被子植物 } \\
\text { Ratio of gymno- } \\
\text { sperms to angio- } \\
\text { sperms }\end{array}$} & 变量 Variables & \multirow[t]{3}{*}{0.734} & MAT & AET & PR & MAPano \\
\hline & 偏决定系数 Partial $R^{2}$ & & 0.413 & 0.061 & 0.005 & 0.010 \\
\hline & $\begin{array}{l}\text { 标准化系数 } \\
\text { Standardized coefficient }\end{array}$ & & -0.635 & -0.257 & -0.055 & 0.054 \\
\hline \multirow{3}{*}{$\begin{array}{l}\text { 松柏亚纲 } \\
\text { Pinidae }\end{array}$} & 变量 Variables & \multirow[t]{3}{*}{0.526} & MAT & MI & ER & MATano \\
\hline & 偏决定系数 Partial $R^{2}$ & & 0.135 & 0.172 & 0.119 & 0.001 \\
\hline & $\begin{array}{l}\text { 标准化系数 } \\
\text { Standardized coefficient }\end{array}$ & & 0.415 & 0.387 & 0.335 & 0.038 \\
\hline \multirow{3}{*}{$\begin{array}{l}\text { 松科 } \\
\text { Pinaceae }\end{array}$} & 变量 Variables & \multirow[t]{3}{*}{0.331} & MAT & MI & ER & MATano \\
\hline & 偏决定系数 Partial $R^{2}$ & & 0.008 & 0.194 & 0.057 & 0.033 \\
\hline & $\begin{array}{l}\text { 标准化系数 } \\
\text { Standardized coefficient }\end{array}$ & & 0.122 & 0.480 & 0.277 & 0.207 \\
\hline \multirow{3}{*}{$\begin{array}{l}\text { 柏科 } \\
\text { Cupressaceae }\end{array}$} & 变量 Variables & \multirow[t]{3}{*}{0.360} & MAT & MI & ER & MAPano \\
\hline & 偏决定系数 Partial $R^{2}$ & & 0.107 & 0.080 & 0.084 & 0.026 \\
\hline & $\begin{array}{l}\text { 标准化系数 } \\
\text { Standardized coefficient }\end{array}$ & & 0.314 & 0.290 & 0.311 & -0.126 \\
\hline \multirow{3}{*}{$\begin{array}{l}\text { 罗汉松科 } \\
\text { Podocarpaceae }\end{array}$} & 变量 Variables & \multirow[t]{3}{*}{0.370} & PET & MI & $\mathrm{TR}$ & MATano \\
\hline & 偏决定系数 Partial $R^{2}$ & & 0.034 & 0.013 & 0.052 & 0.144 \\
\hline & $\begin{array}{l}\text { 标准化系数 } \\
\text { Standardized coefficient }\end{array}$ & & 0.366 & 0.169 & 0.408 & -0.538 \\
\hline \multirow{3}{*}{$\begin{array}{l}\text { 红豆杉科 } \\
\text { Taxaceae }\end{array}$} & 变量 Variables & \multirow[t]{3}{*}{0.282} & MAT & PCQ & ER & MAPano \\
\hline & 偏决定系数 Partial $R^{2}$ & & 0.087 & 0.059 & 0.099 & 0.046 \\
\hline & $\begin{array}{l}\text { 标准化系数 Standard- } \\
\text { ized coefficient }\end{array}$ & & 0.454 & 0.220 & 0.498 & -0.127 \\
\hline \multirow{3}{*}{$\begin{array}{l}\text { 买麻藤亚纲 } \\
\text { Gnetidae }\end{array}$} & 变量 Variables & \multirow[t]{3}{*}{0.364} & MTCQ & MI & PR & MATano \\
\hline & 偏决定系数 Partial $R^{2}$ & & 0.162 & 0.128 & 0.019 & 0.119 \\
\hline & $\begin{array}{l}\text { 标准化系数 } \\
\text { Standardized coefficient }\end{array}$ & & -0.574 & -0.468 & 0.160 & -0.424 \\
\hline \multirow{3}{*}{$\begin{array}{l}\text { 买麻藤科 } \\
\text { Gnetaceae }\end{array}$} & 变量 Variables & \multirow[t]{3}{*}{0.314} & MTCQ & PCQ & ER & MATano \\
\hline & 偏决定系数 Partial $R^{2}$ & & 0.034 & 0.018 & 0.074 & 0.178 \\
\hline & $\begin{array}{l}\text { 标准化系数 } \\
\text { Standardized coefficient }\end{array}$ & & 0.551 & -0.124 & 0.569 & -0.704 \\
\hline \multirow{3}{*}{$\begin{array}{l}\text { 麻黄科 } \\
\text { Ephedraceae }\end{array}$} & 变量 Variables & \multirow[t]{3}{*}{0.431} & MTCQ & AET & PR & MATano \\
\hline & 偏决定系数 Partial $R^{2}$ & & 0.141 & 0.186 & 0.022 & 0.062 \\
\hline & $\begin{array}{l}\text { 标准化系数 } \\
\text { Standardized coefficient }\end{array}$ & & -0.571 & -0.830 & 0.156 & -0.296 \\
\hline \multirow{3}{*}{$\begin{array}{l}\text { 苏铁亚纲 } \\
\text { Cyacadidae }\end{array}$} & 变量 Variables & \multirow[t]{3}{*}{0.416} & MTCQ & PCQ & $\mathrm{PR}$ & MATano \\
\hline & 偏决定系数 Partial $R^{2}$ & & 0.028 & 0.096 & 0.034 & 0.151 \\
\hline & $\begin{array}{l}\text { 标准化系数 } \\
\text { Standardized coefficient }\end{array}$ & & 0.478 & -0.221 & 0.334 & -0.663 \\
\hline
\end{tabular}

MAT: 年均温; MTCQ: 最冷季均温; WI: 温暖指数; PET: 潜在蒸散量; MAP: 年降水; PCQ: 最冷季降水; MI: 湿润指数; AET: 实际蒸散量; ER: 海拔高差; TR: 年均温空间变异; PR: 年降水空间变异; MATano: 末次冰期以来年均温变化; MAPano: 末次冰期以来年降水变化。

MAT, Mean annual temperature; MTCQ, Mean temperature of coldest month; WI, Warmth index; PET, potential evapotranspiration; MAP, Annual precipitation; PCQ, Precipitation of coldest month; MI, Moist index; AET, Actual evapotranspiration; ER, Elevational range; TR, Environmental heterogeneity of temperature; PR, Environmental heterogeneity of precipitation; MATano, Temperature anomaly since the Last Glacial Maximum; MAPano, Precipitation anomaly since the Last Glacial Maximum. 


\section{4 裸子植物与被子植物比例的空间格局}

中国裸子植物与被子植物物种多样性的比例 在空间上呈现西北高、东南低的格局(图1b)。约以 $400 \mathrm{~mm}$ 年等降水量线为界, 其东部裸子植物与被 子植物物种多样性的比例低于 0.060 , 而其西部地 区这一比例则较高, 最高值位于青藏高原中部, 约 为 0.375 (图1b)。

裸子植物与被子植物的比例与除海拔高差、年 均温空间变异和末次冰期以来降水变化之外的全 部环境因子显著相关 $(P<0.05)$, 除与末次冰期以来 的气温变化 $(r=0.517)$ 呈正相关外, 与其他变量呈 负相关, 其中与年均温 $(r=-0.826)$ 、实际蒸散量 $(r=$ $-0.810)$ 、最冷季均温 $(r=-0.805)$ 相关性最强(表1)。 在多元回归分析中, 年均温是最重要的变量(偏决 定系数为 0.413$)$, 年均温与实际蒸散量、年降水空间 变异和末次冰期以来的降水变化共同解释了 $73.4 \%$ 的格局(表2)。

\section{3 讨论}

\section{1 中国裸子植物多样性格局}

中国有丰富的裸子植物，拥有世界12个科中的 8 个。整体上, 中国裸子植物的物种多样性呈南高北 低的格局, 这与中国全部木本植物物种多样性格局 相似(Wang et al, 2011), 也与中国许多动植物类群 的分布格局类似，如兰科植物(Zhang et al, 2015)、蝴 蝶(Chen et al, 2014)和陆生哺乳动物(林金等, 2009) 等。松柏亚纲是中国裸子植物的主要成分, 占全部 裸子植物种类的 $80 \%$ 以上; 而其中的松科与柏科占 松柏亚纲物种的近 $80 \%$, 因此松柏两科的西南地区 高、北方地区低的物种多样性格局很大程度上影响 了裸子植物的整体分布格局。另一方面，不同科的 裸子植物生态习性各异, 它们在不同环境因素的驱 动下, 形成了差异明显的分布格局和多样性中心 (图1, 2): 喜湿热的苏铁科、买麻藤科、罗汉松科和 红豆杉科几乎全部分布在南方地区，松科的物种多 样性中心位于中国西南的横断山区, 而麻黄科则在 西北地区种类较多。这些共性与差异形成了裸子植 物复杂的多样性格局(李果等, 2009)。

回归分析的结果表明, 生境异质性和水分是影 响裸子植物整体物种多样性格局的主要因素(表1)。 在地形、水分、能量空间异质性高的地区, 裸子植 物的物种多样性也高。这与生境异质性假说相符
(Rosenzweig, 1995)。对全球192个地区的生物多样 性格局的荟萃分析也表明, 生境越复杂的地区, 生 物多样性越高(Stein et al, 2014)。生境异质性主要通 过以下途径影响物种多样性：首先，生境复杂的地 区能够提供更加丰富的栖息地类型和更多种可供 生物利用的资源，从而提供更多的生态位供更多生 物生存(Currie, 1991); 其次, 生境复杂的地区可以 在环境条件改变或者气候变化时为生物提供避难 所，从而保存更多生物(Cun \& Wang, 2010; Fjeldså et al, 2012); 第三, 复杂的环境也可以产生隔离作 用，从而促进物种分化(Cun \& Wang, 2010; Xing \& Ree, 2017)。横断山区很高的裸子植物多样性可能就 是环境异质性作用的结果。自第三纪中期以来，由 于多样的生境、气候的稳定性等(López-Pujol et al, 2011; Sandel et al, 2011; Xing \& Ree, 2017), 横断山 区一直是裸子植物的避难所, 保留了大量的古老裸 子植物物种, 如台湾杉(Taiwania cryptomerioides)、 云杉(Picea spp.)等(Ran et al, 2006; 叶建飞等, 2012), 增加了当地的裸子植物多样性(López-Pujol et al, 2011)。在始新世末期(约34 Ma), 全球气温开始下降, 包括松柏类如冷杉属(Abies)、云杉属等在内的许多 北极-第三纪成分的物种向南迁入横断山地区并在 此分化(孙航, 2002; Wei \& Wang, 2004; Ran et al, 2006; 向小果等, 2006)。另外, 在上新世和更新世 (约 5.33-0.13 Ma)时期, 横断山形成了高山、河谷、 峡谷等复杂的地形, 从而形成了复杂的气候和生境, 通过异域种化和生态成种过程, 可能促进了裸子植 物新物种的产生(孙航, 2002; López-Pujol et al 2011)。作为古老物种的避难所和新物种的摇篮，横 断山区成为了裸子植物物种多样性中心。

水分因素也与裸子植物物种多样性有较显著 的相关性(表1), 水分越丰富的地区，裸子植物的物 种多样性越高。这一结果与以往关于物种多样性格 局的水热动态假说具有一致性(O’Brien, 1998; Currie et al, 2004)。Hawkins等(2003)对21项关于大尺度植 物多样性格局的研究进行整合和重分析后发现, 除 了美国北部的木本植物外，其他地区的植物多样性 格局均受到水分(降雨和降水)或者水热动态(实际 蒸散量、生产力、净初级生产力或净地面初级生产 力)的影响; 特别是在温暖的热带或亚热带地区, 水 分是影响植物物种多样性的主要因素。在气温适宜 时, 液态水的存在会影响植物生理活动的效率 
(O'Brien, 1998)。整体而言，水分条件更好的地区能 够提供更多生态位，裸子植物的多样性更高。

与以往关于东亚地区木本被子植物物种多样 性格局的研究结果不同(Wang et al, 2011), 我们发 现, 能量因子不是裸子植物物种多样性的主要限制 因素。在能量因素中, 年均温和最冷季均温与裸子 植物多样性呈显著负相关, 而温暖指数和潜在蒸散 量对裸子植物多样性的影响不显著。但相对于其他 因子, 能量因子(包括年均温和最冷季均温)对裸子 植物多样性的影响较小(表1)。Hawkins等(2003)的荟 萃分析也表明, 对于大部分地区的植物多样性, 能 量都不是主要的解释因子: 在能量较低的北方地区, 能量和水分共同主导物种多样性格局; 而在能量充 足的南方地区, 能量则不构成主要限制因子。这可 能是因为在能量充足的地区各类群均能够在适宜 的温度中进行正常的生长繁殖活动, 所以竞争集中 于水分等有限的资源上(Hawkins et al, 2003)。

现代气候因子对物种多样性格局的作用在不
反。具体而言, 水分因子与麻黄科物种多样性呈较 强负相关, 这与麻黄类对干旱环境的适应有关。麻 黄类叶片膜质化、具有绿色同化枝、根系发达(牟凤 娟等, 2016); 同时，麻黄类多为灌木，地下结构发 达、地上部分较为矮小, 能够较好地保有水分, 非 常适应干旱环境(李正理，1981; 牟凤娟等，2016)。 在中国(图2)和世界(Fragnière et al, 2015)范围内, 麻 黄类在干旱或高海拔环境中均具有较高的物种多 样性。与麻黄类相反, 水分与松柏亚纲各科的物种 多样性则呈显著正相关。这种复杂的关系也说明了 各类群有着各自独特的进化历史和生态适应性, 不 同因素的共同作用形成了现代的裸子植物多样性 格局。

除了现代气候的影响, 进化与地质历史因素也 可能影响现代物种多样性格局。值得一提的是, 我 们的结果显示, 末次冰期以来的气温上升与裸子植 物多样性呈显著负相关(表1)。我们推测, 这可能是 因为第四纪冰期时的剧烈降温显著影响了中国北 方地区，使大量物种的分布区向南迁移; 而冰期结 束后, 很多物种并未向北扩散至其气候适合的地区 (Wang et al, 2012a, b)。而在温度变化较小的地区, 更多的物种被保存了下来。比如, 罗汉松科、红豆 杉科、苏铁科和买麻藤科是喜湿热环境的较为古老
的类群(Wu \& Raven, 1999; Leslie et al, 2012), 其物 种多样性在北方地区很低(表1)。这可能正是由于在 第四纪气候旋回中, 这些类群在气候变化剧烈的北 方地区大量灭绝, 而仅在气候稳定的南方保存下 来。这与中国北方的孢粉记录是一致的。在第四纪 早更新世，气候相对于今天更加温暖湿润，华北乃 至大兴安岭均有罗汉松科的狍粉记录, 而在冰期时, 这些地区就已不再有这些热带、亚热带植物成分(纪 仁生，2007)。在更长的进化时间尺度上，裸子植物 也随着气候变化不断发生灭绝、迁移和种化。如自 第三纪中期以来全球气温下降，银杏类(Ginkgoales)、水杉类(Metasequoia)、银杉类(Cathaya)等许 多曾经繁盛的古老裸子植物类群几乎全部灭绝，只 剩极少子遗物种在气候较为稳定的山地地区保存 了下来(Hsieh, 1992; Hu, 1998; Wang et al, 1998)。但 另一方面, 第三纪中期以来的这一寒冷化过程也促 进了物种分布区的改变和新物种的产生。如冷杉植 物在第三纪气候变冷后开始向南迁移, 并不断在新 环境中演化出新的物种(向小果等, 2006)。除了历史 气候, 地质事件也可能显著影响了裸子植物多样性 格局。如中中新世(约13 Ma)以来的青藏高原隆起和 由此造成的干旱化, 可能促进了麻黄类在中亚地区 的快速分化(Qin et al, 2013)。

此外, 在东部平原和西部盆地地区, 人类活动 干扰强，可能会造成这些地区部分裸子植物物种的 区域性灭绝(Hong, 1998; Gao et al, 2009; 李果等, 2009), 从而降低当地裸子植物多样性, 但这一影响 有待于进一步评估。目前, 对于裸子植物大尺度多 样性格局成因的研究仍较为有限, 全面研究各种因 素的作用, 将有利于更好地认识裸子植物多样性格 局的成因, 从而在未来的气候变化中更好地保护裸 子植物的生物多样性。

\section{2 裸子植物与被子植物物种多样性比例的地理} 格局

在全国尺度，裸子植物与被子植物物种多样性 比例的空间格局有两个特点。第一, 整体比例较低, 在大部分地区比例低于 0.1 。这是因为被子植物的物 种多样性远高于裸子植物。但另一方面, 中国木本 被子植物约有11,000种(Fang et al, 2011), 在全国尺 度上裸子植物与被子植物物种多样性的比例约为 0.018, 远低于二者在局地区系中的比例。由此可见, 裸子植物的生态优势一定程度上弥补了其物种多 
样性的劣势, 使得其在局地区系中的比例显著高于 全国整体水平(Brodribb et al, 2012)。第二, 二者物 种多样性的比例具有明显的空间分异。具体而言, 在中国南部、东部等水热条件较为优越的地区, 裸 子植物比例很低, 而在北部、西部(如青藏高原)等干 冷地区, 裸子植物比例较高。这些发现也进一步得 到回归分析的支持(表1)。

裸子植物比例在干冷地区较高可能与裸子植 物对低温与干旱的良好适应有关。近期对松柏亚 纲、买麻藤类和被子植物基因组的比较研究表明, 裸子植物的主要成分松柏亚纲的基因组中产生了 一系列抗寒性适应(Yeaman et al, 2016; Wan et al, 2018)。有研究认为, 在低温环境中, 裸子植物的管 胞结构比起被子植物的导管系统的水分运输效率 更高, 而且可以避免冻融栓塞(Bond, 1989; Brodribb et al, 2012; Kozlowski et al, 2015)。在叶片结构上, 大部分裸子植物的叶片为针状、披针状、鳞状等细 长形状，具有下陷的气孔、发达的角质层和维管束, 可以较好地抵抗干冷环境(Wu \& Raven, 1999; Farjon, 2010; Pittermann et al, 2012)。一些北温带的松 柏类, 如加州刺柏(Juniperus californica), 其较高的 木材密度也使其能适应干旱的环境(Hacke et al, 2001; Pittermann et al, 2006; Chave et al, 2009; Pittermann et al, 2012)。另外, 在干旱和土壤贫癐的地 区, 树冠层形成的遮挡较少, 光线较为充足, 裸子 植物也可以高效地利用针叶进行光合作用(Coomes \& Grubb, 2000)。因此, 相对被子植物而言, 裸子植 物对于干冷环境的适应性更强。所以, 在干冷主导 的中国西部、北部以及青藏高原地区, 裸子植物的 比例相较湿润区更高。与此相反, 在温暖湿润的西 南、南部和东部地区, 大部分裸子植物类群的叶片 面积小、光合作用弱, 管胞输水效率低于被子植物 的导管系统(Bond, 1989; Kozlowski et al, 2015), 使 其在水热充足的地区对光和水等资源的竞争力弱 于被子植物。因此, 在中国东南部地区, 虽然裸子 植物的物种多样性较西部地区高, 但被子植物的种 类更为丰富, 裸子植物物种多样性比例更低。在温 暖湿润地区, 仅小部分裸子植物类群(如罗汉松科 和红豆杉科物种等)通过一系列适应性性状, 如扁 平宽大的叶片、叶状茎以及类似于被子植物的叶脉 结构, 提高了光合和水分运输效率, 从而能够在与 被子植物的竞争中生存(Biffin et al, 2012)。
在末次冰期以来气温变化较大的地区, 裸子植 物相对于被子植物的比例也更高。这可能是因为裸 子植物特别是松科在冰期后的环境中扩散与定居 的速度快于被子植物 (Gear \& Huntley，1991; Brodribb et al, 2012): 其管胞结构带来的抗冻融栓 塞属性、光合效率高的针叶(Brodribb \& Feild, 2008) 和低木材密度带来的较快的生长速度 (Becker, 2000), 都有利于其在冰期后与被子植物竞争。另外, 末次冰期以来气候变化剧烈的地区，也通常是现代 环境较为寒冷的地区, 在这些地区中裸子植物的竞 争力也更强, 因此相对比例也更高(Sperry et al, 2006; Fragnière et al, 2015; Kozlowski et al, 2015)。

\section{参考文献}

Araújo MB, Nogués-Bravo D, Diniz-Filho JAF, Haywood AM, Valdes PJ, Rahbek C (2008) Quaternary climate changes explain diversity among reptiles and amphibians. Ecography, 31, 8-15.

Augusto L, Davies TJ, Delzon S, de Schrijver A (2014) The enigma of the rise of angiosperms: Can we untie the knot? Ecology Letters, 17, 1326-1338.

Becker P (2000) Competition in the regeneration niche between conifers and angiosperms: Bond's slow seedling hypothesis. Functional Ecology, 14, 401-412.

Biffin E, Brodribb TJ, Hill RS, Thomas P, Lowe AJ (2012) Leaf evolution in Southern Hemisphere conifers tracks the angiosperm ecological radiation. Proceedings of the Royal Society B: Biological Sciences, 279, 341-348.

Bond W (1989) The tortoise and the hare: Ecology of angiosperm dominance and gymnosperm persistence. Biological Journal of the Linnean Society, 36, 227-249.

Brodribb TJ, Feild TS (2008) Evolutionary significance of a flat-leaved Pinus in Vietnamese rainforest. New Phytologist, 178, 201-209.

Brodribb TJ, Pittermann J, Coomes DA (2012) Elegance versus speed: Examining the competition between conifer and angiosperm trees. International Journal of Plant Sciences, 173, 673-694.

Chave J, Coomes D, Jansen S, Lewis SL, Swenson NG, Zanne AE (2009) Towards a worldwide wood economics spectrum. Ecology Letters, 12, 351-366.

Chen S, Mao L, Zhang J, Zhou K, Gao J (2014) Environmental determinants of geographic butterfly richness pattern in eastern China. Biodiversity \& Conservation, 23, 1453-1467.

Condamine FL, Nagalingum NS, Marshall CR, Morlon H (2015) Origin and diversification of living cycads: A cautionary tale on the impact of the branching process prior in Bayesian molecular dating. BMC Evolutionary Biology, 15, 65-65. 
Coomes DA, Grubb PJ (2000) Impacts of root competition in forests and woodlands: A theoretical framework and review of experiments. Ecological Monographs, 70, 171-207.

Cun YZ, Wang XQ (2010) Plant recolonization in the Himalaya from the southeastern Qinghai-Tibetan Plateau: Geographical isolation contributed to high population differentiation. Molecular Phylogenetics \& Evolution, 56, 972-982.

Currie DJ (1991) Energy and large-scale patterns of animaland plant-species richness. The American Naturalist, 137, 27-49.

Currie DJ, Mittelbach GG, Cornell HV, Field R, Guegan J, Hawkins BA, Kaufman DM, Kerr JT, Oberdorff T, Obrien EM, Turner JRG (2004) Predictions and tests of climate-based hypotheses of broad-scale variation in taxonomic richness. Ecology Letters, 7, 1121-1134.

Dutilleul P, Clifford P, Richardson S, Hemon D (1993) Modifying the $t$ test for assessing the correlation between two spatial processes. Biometrics, 49, 305-314.

Fang JY, Yoda K (1990) Climate and vegetation in China. III. Water balance and distribution of vegetation. Ecological Research, 5, 9-23.

Fang JY, Wang ZH, Tang ZY (2011) Atlas of Woody Plants in China: Distribution and Climate. Higher Education Press, Beijing \& Springer, Berlin.

Farjon A (2010) A Handbook of the World's Conifers. Brill Academic Publishers, Netherlands.

Fjeldså J, Bowie RCK, Rahbek C (2012) The role of mountain ranges in the diversification of birds. Annual Review of Ecology, Evolution, and Systematics, 43, 249-265.

Fragnière Y, Bétrisey S, Cardinaux L, Stoffel M, Kozlowski G (2015) Fighting their last stand? A global analysis of the distribution and conservation status of gymnosperms. Journal of Biogeography, 42, 809-820.

Gao JF, Ma KM, Feng ZW, Qi J, Feng Y (2009) Coupling effects of altitude and human disturbance on landscape and plant diversity in the vicinity of mountain villages of Beijing, China. Acta Ecologica Sinica, 29, 56-61.

Gear AJ, Huntley B (1991) Rapid changes in the range limits of Scots Pine 4000 years ago. Science, 251, 544-547.

Gerrienne P, Meyer-Berthaud B, Fairon-Demaret M, Streel M, Steemans P (2004) Runcaria, a Middle Devonian seed plant precursor. Science, 306, 856-858.

Hacke UG, Sperry JS, Pockman WT, Davis SD (2001) Trends in wood density and structure are linked to prevention of xylem implosion by negative pressure. Oecologia, 126, 457-461.

Hawkins BA, Field R, Cornell HV, Currie DJ, Guegan J, Kaufman DM, Kerr JT, Mittelbach GG, Oberdorff T, O’brien EM, Porter EE, Turner JRG (2003) Energy, water, and broad-scale geographic patterns of species richness. Ecology, 84, 3105-3117.

Hill K (2012) The Cycad Pages. http://www.succulentplant.com/families/cycadaceae.html. (accessed on 2018-03-01)
Hong SK (1998) Changes in landscape patterns and vegetation process in the Far-Eastern cultural landscapes: Human activity on pine-dominated secondary vegetations in Korea and Japan. Phytocoenologia, 28, 45-66.

Hsieh L (1992) Origin and distribution of Ginkgo biloba. The Forestry Chronicle, 68, 612-613.

Hu HH (1998) How Metasequoia, the "living fossil”, was discovered in China. Arnoldia, 58, 4-7.

Jetz W, Rahbek C (2002) Geographic range size and determinants of avian species richness. Science, 297, 1548.

Ji RS (2007) Forest changes in Inner Mongolia-Forest changes during geological times. Inner Mongolia Forestry Investigation and Design, (S1), 1-94, 106-108. (in Chinese) [纪仁生 (2007) 内蒙古森林变迁一一地史时期森林的变 迁. 内蒙古林业调查设计, (S1), 1-94, 106-108.]

Kozlowski G, Stoffel M, Betrisey S, Cardinaux L, Mota M (2015) Hydrophobia of gymnosperms: Myth or reality? A global analysis. Ecohydrology, 8, 105-112.

Kreft H, Jetz W (2007) Global patterns and determinants of vascular plant diversity. Proceedings of the National Academy of Sciences, USA, 104, 5925-5930.

Latham RE, Ricklefs RE (1993) Global patterns of tree species richness in moist forests: Energy-diversity theory does not account for variation in species richness. Oikos, 67, 325333.

Lennon JJ (2000) Red-shifts and red herrings in geographical ecology. Ecography, 23, 101-113.

Leslie AB, Beaulieu JM, Rai HS, Crane PR, Donoghue MJ, Mathews S (2012) Hemisphere-scale differences in conifer evolutionary dynamics. Proceedings of the National Academy of Sciences, USA, 109, 16217-16221.

Li G, Shen ZH, Ying TS, Fang JY (2009) The spatial pattern of species richness and diversity centers of gymnosperm in China. Biodiversity Science, 17, 272-279. (in Chinese with English abstract) [李果, 沈泽昊, 应俊生, 方精云 (2009) 中国裸子植物物种丰富度空间格局与多样性中心. 生物 多样性, 17, 272-279.]

Li ZL (1981) Morphology and structure of drought vegetation. Biology Journal, (4), 9-12. (in Chinese) [李正理 (1981) 旱 生植物的形态和结构. 生物学通报, (4), 9-12.]

Lin X, Wang ZH, Tang ZY, Zhao SQ, Fang JY (2009) Geographic patterns and environmental correlates of terrestrial mammal species richness in China. Biodiversity Science, 17, 652-663. (in Chinese with English abstract) [林崟金, 王志恒, 唐志尧, 赵淑清, 方精云 (2009) 中国陆栖哺乳动物物种 丰富度的地理格局及其与环境因子的关系. 生物多样性, 17, 652-663.]

López-Pujol J, Zhang FM, Sun HQ, Ying TS, Ge S (2011) Mountains of southern China as "plant museums" and "plant cradles”: Evolutionary and conservation insights. Mountain Research and Development, 31, 261-269.

Maurer BA, Rosenzweig ML (1996) Species Diversity in Space and Time. Ecology, 77, 1314. 
McCain CM (2009) Global analysis of bird elevational diversity. Global Ecology and Biogeography, 18, 346-360.

Mou FJ, Li JP, Chen LP, Li YG (2016) The progress on the relationship between the morphological and anatomical character and the resistant. Journal of Fujian Forestry Science \& Technology, 43, 237-243. (in Chinese with English abstract) [牟凤娟, 李军萍, 陈丽萍, 李一果 (2016) 裸子 植物形态解剖结构特征与抗旱性研究进展. 福建林业科 技, 43, 237-243.]

Nagalingum NS, Marshall CR, Quental TB, Rai HS, Little DP, Mathews S (2011) Recent synchronous radiation of a living fossil. Science, 334, 796-799.

O’Brien EM (1998) Water-energy dynamics, climate, and prediction of woody plant species richness: An interim general model. Journal of Biogeography, 25, 379-398.

Osorio F, Vallejos R, Cuevas F (2016) SpatialPack: Computing the association between two spatial processes. arXiv preprint arXiv:1611.05289.

Palmer MW (1994) Variation in species richness: Towards a unification of hypotheses. Folia Geobotanica et Phytotaxonomica, 29, 511.

Pittermann J, Sperry JS, Wheeler JK, Hacke UG, Sikkema EH (2006) Mechanical reinforcement of tracheids compromises the hydraulic efficiency of conifer xylem. Plant Cell \& Environment, 29, 1618.

Pittermann J, Stuart SA, Dawson TE, Moreau A (2012) Cenozoic climate change shaped the evolutionary ecophysiology of the Cupressaceae conifers. Proceedings of the National Academy of Sciences, USA, 109, 9647-9652.

Qian H, Jin Y, Ricklefs RE (2017) Phylogenetic diversity anomaly in angiosperms between eastern Asia and eastern North America. Proceedings of the National Academy of Sciences, USA, 114, 11452-11457.

Qin AL, Wang MM, Cun YZ, Yang FS, Wang SS, Ran JH, Wang XQ (2013) Phylogeographic evidence for a link of species divergence of Ephedra in the Qinghai-Tibetan Plateau and adjacent regions to the Miocene Asian Aridification. PLoS ONE, 8, e56243.

Ran JH, Wei XX, Wang XQ (2006) Molecular phylogeny and biogeography of Picea (Pinaceae): Implications for phylogeographical studies using cytoplasmic haplotypes. Molecular Phylogenetics and Evolution, 41, 405-419.

R Core Team (2016) R: A Language and Environment for Statistical Computing. https://www.R-project.org/. (accessed on 2018-01-01)

Rosenzweig ML (1995) Species Diversity in Space and Time. Cambridge University Press, Cambridge.

Rueda M, Godoy O, Hawkins BA (2017) Spatial and evolutionary parallelism between shade and drought tolerance explains the distributions of conifers in the conterminous United States. Global Ecology and Biogeography, 26, 31-42.

Sandel B, Arge L, Dalsgaard B, Davies RG, Gaston KJ, Sutherland WJ, Svenning J (2011) The influence of Late Qua- ternary climate-change velocity on species endemism. Science, 334, 660-664.

Sperry JS, Hacke UG, Pittermann J (2006) Size and function in conifer tracheids and angiosperm vessels. American Journal of Botany, 93, 1490-1500.

Stein A, Gerstner K, Kreft H (2014) Environmental heterogeneity as a universal driver of species richness across taxa, biomes and spatial scales. Ecology Letters, 17, 866-880.

Stein A, Beck J, Meyer C, Waldmann E, Weigelt P, Kreft H (2015) Differential effects of environmental heterogeneity on global mammal species richness. Global Ecology and Biogeography, 24, 1072-1083.

Sun H (2002) Evolution of Arctic-Tertiary flora in Himalayan-Hengduan Mountains. Acta Botanica Yunnanica, 24, 671-688. (in Chinese with English abstract) [孙航 (2002) 北极一第三纪成分在喜马拉雅一横断山的发展及演化. 云南植物研究, 24, 671-688.]

Svenning JC, Skov F (2007) Ice age legacies in the geographical distribution of tree species richness in Europe. Global Ecology and Biogeography, 16, 234-245.

Taylor EL, Taylor TN, Krings M (2009) Paleobotany: The Biology and Evolution of Fossil Plants. Academic Press, Waltham.

Thornthwaite CW, Hare FK (1955) Climatic classification in forest. Unasylva, 9, 51-59.

Wan T, Liu ZM, Li LF, Leitch AR, Leitch IJ, Lohaus R, Liu ZJ, Xin HP, Gong YB, Liu Y, Wang WC, Chen LY, Yang Y, Kelly LJ, Yang J, Huang JL, Li Z, Liu P, Zhang L, Liu HM, Wang H, Deng SH, Liu M, Li J, Ma L, Liu Y, Lei Y, Xu W, Wu LQ, Liu F, Ma Q, Yu XR, Jiang Z, Zhang GQ, Li SH, Li RQ, Zhang SZ, Wang QF, de Peer YV, Zhang JB, Wang XM (2018) A genome for gnetophytes and early evolution of seed plants. Nature Plants, 4, 82-89.

Wang XQ, Han Y, Hong DY (1998) A molecular systematic study of Cathaya, a relic genus of the Pinaceae in China. Plant Systematics and Evolution, 213, 165-172.

Wang ZH, Fang JY, Tang ZY, Lin X (2011) Patterns, determinants and models of woody plant diversity in China. Proceedings of the Royal Society B: Biological Sciences, 278, 2122-2132.

Wang ZH, Fang JY, Tang ZY, Shi L (2012a) Geographical patterns in the beta diversity of China's woody plants: The influence of space, environment and range size. Ecography, 35, 1092-1102.

Wang ZH, Fang JY, Tang ZY, Lin X (2012b) Relative role of contemporary environment versus history in shaping diversity patterns of China's woody plants. Ecography, 35, 1124-1133.

Wang ZH, Tang ZY, Fang JY (2009) The species-energy hypothesis as a mechanism for species richness patterns. Biodiversity Science 17, 613-624. (in Chinese with English abstract) [王志恒, 唐志尧, 方精云 (2009) 物种多样性地 理格局的能量假说. 生物多样性, 17, 613-624.] 
Wei XX, Wang XQ (2004) Recolonization and radiation in Larix (Pinaceae): Evidence from nuclear ribosomal DNA paralogues. Molecular Ecology, 13, 3115-3123.

Wu Z, Raven P (1999) Flora of China, Vol. 4. Science Press, Beijing \& Missouri Botanical Garden Press, St. Louis.

Xiang XG, Cao M, Zhou ZK (2006) Fossil history and modern distribution of the genus Abies (Pinaceae). Acta Botanica Yunnanica, 28, 439-452. (in Chinese with English abstract) [向小果, 曹明, 周浙昆 (2006) 松科冷杉属植物的化石 历史和现代分布. 云南植物研究, 28, 439-452.]

Xing YW, Ree RH (2017) Uplift-driven diversification in the Hengduan Mountains, a temperate biodiversity hotspot. Proceedings of the National Academy of Sciences, USA, 114, E3444.

Yang Y, Wang ZH, Xu XT (2017) Taxonomy and Distribution of Global Gymnosperms. Shanghai Scientific and Technical Publishers, Shanghai. (in Chinese) [杨永, 王志恒, 徐晓婷 (2017) 世界裸子植物的分类和地理分布. 上海科学技术 出版社, 上海.]

Yeaman S, Hodgins KA, Lotterhos KE, Suren H, Nadeau S,
Degner JC, Nurkowski KA, Smets P, Wang T, Gray LK, Liepe KJ, Hamann A, Holliday J, Whitlock MC, Rieseberg LH, Aitken SN (2016) Convergent local adaptation to climate in distantly related conifers. Science, 353, 1431-1433.

Ye JF, Chen ZD, Liu B, Qin HN, Yang Y (2012) Disjunct distribution of vascular plants between southwestern area and Taiwan area in China: Disjunct distribution of vascular plants between southwestern area and Taiwan area in China. Biodiversity Science, 20, 482-494. (in Chinese with English abstract) [叶建飞, 陈之端，刘冰，覃海宁，杨永 (2012) 中国西南与台湾地区维管植物的间断分布格局及形成机 制. 生物多样性, 20, 482-494.]

Ying J, Chen M, Zhang H (2003) Atlas of the Gymnosperms of China. China Science \& Technology Press, Beijing.

Zhang ZJ, Yan YJ, Tian Y, Li JS, He JS, Tang ZY (2015) Distribution and conservation of orchid species richness in China. Biological Conservation, 181, 64-72.

(责任编委：王国宏 责任编辑：黄祥忠、周玉荣)

\section{附录 Supplementary Material}

附录1 本文所用的中国的环境因子之间的Pearson相关性矩阵

Appendix 1 Pearson correlation coefficient matrix between all used environmental determinants in China http://www.biodiversity-science.net/fileup/PDF/2018098-1.pdf 
附录 1 本文所用的中国的环境因子之间的 Pearson 相关性矩阵。MAT: 年均温; MTCQ: 最冷季均温; WI: 温暖指数; PET: 潜在蒸散量; MAP: 年降水; PCQ: 最冷季降水; MI: 湿润指数; AET: 实际蒸散量; ER: 海拔高差; TR: 年均温空间变异; PR: 年降水空间变异; MATano: 末次冰期以来年均温变化; MAPano: 末次冰期以来年降水变化。

Appendix 1 Pearson correlation coefficient matrix between all used environmental determinants in China. MAT, Mean annual temperature; MTCQ, Mean temperature of coldest month; WI, Warmth index; PET, Potential evapotranspiration; MAP, Annual precipitation; PCQ, Precipitation of coldest month; MI, Moist index; AET, Actual evapotranspiration; ER, Elevational range; TR, Environmental heterogeneity of temperature; PR, Environmental heterogeneity of precipitation; MATano, Temperature anomaly since the Last Glacial Maximum; MAPano, Precipitation anomaly since the Last Glacial Maximum.

\begin{tabular}{|c|c|c|c|c|c|c|c|c|c|c|c|c|c|}
\hline & MAT & MTCQ & WI & PET & MAP & PCQ & MI & AET & ER & $\mathrm{TR}$ & PR & MATano & MAPano \\
\hline MAT & 1.000 & & & & & & & & & & & & \\
\hline MTCQ & 0.918 & 1.000 & & & & & & & & & & & \\
\hline WI & 0.967 & 0.840 & 1.000 & & & & & & & & & & \\
\hline PET & 0.966 & 0.819 & 0.993 & 1.000 & & & & & & & & & \\
\hline MAP & 0.694 & 0.768 & 0.679 & 0.646 & 1.000 & & & & & & & & \\
\hline PCQ & 0.618 & 0.655 & 0.628 & 0.607 & 0.839 & 1.000 & & & & & & & \\
\hline MI & 0.345 & 0.505 & 0.283 & 0.253 & 0.870 & 0.647 & 1.000 & & & & & & \\
\hline AET & 0.699 & 0.737 & 0.699 & 0.675 & 0.928 & 0.730 & 0.780 & 1.000 & & & & & \\
\hline ER & -0.199 & 0.035 & -0.279 & -0.320 & 0.145 & 0.056 & 0.315 & 0.026 & 1.000 & & & & \\
\hline TR & -0.221 & 0.022 & -0.303 & -0.344 & 0.147 & 0.044 & 0.333 & 0.037 & 0.979 & 1.000 & & & \\
\hline PR & 0.320 & 0.463 & 0.262 & 0.231 & 0.709 & 0.526 & 0.740 & 0.675 & 0.556 & 0.574 & 1.000 & & \\
\hline MATano & -0.621 & -0.703 & -0.592 & -0.571 & -0.505 & -0.528 & -0.280 & -0.443 & -0.205 & -0.184 & -0.342 & 1.000 & \\
\hline MAPano & 0.131 & 0.039 & 0.226 & 0.244 & 0.207 & 0.303 & 0.088 & 0.247 & -0.165 & -0.162 & 0.072 & -0.147 & 1.000 \\
\hline
\end{tabular}

